\title{
DOUBLE-BARRELED CONDUIT FOR RIGHT ATRIOVENTRICULAR CONNECTION IN TRICUSPID ATRESIA: A NEW TECHNIQUE
}

\author{
Christos Alexiou, FRCS, ${ }^{a}$ David J. Delany, FRCR, ${ }^{\mathrm{b}}$ Barry R. Keeton, FRCP, FRCPCH, ${ }^{\mathrm{c}}$ and James L. Monro, FRCS, ${ }^{\mathrm{a}}$ \\ Southampton, United Kingdom
}

Homografts used to establish a right atrioventricular connection in patients having tricuspid atresia with a good-sized right ventricle (RV) tend to calcify and become obstructive and nonfunctional. Compression of the homograft by the overlying sternum contributes to this process.

We present a technique whereby an incompressible heterograft and a homograft are inserted side by side between the right atrium (RA) and the RV in a double-barreled fashion. The heterograft protects itself and the homograft, which is inferior to it, from collapsing because of sternal compression. Improved RA-RV blood flow is possible because the much larger combined orifice area offers much lower resistance. Longer patency may be anticipated because of the lack of sternal compression and the improved hemodynamics.

Clinical summary. A murmur was heard in this female

From the Departments of Cardiac Surgery, ${ }^{a}$ Cardiothoracic Radiology, ${ }^{\mathrm{b}}$ and Paediatric Cardiology, ${ }^{\mathrm{c}}$ The General Hospital, Southampton, United Kingdom.

Received for publication March 13, 2000; accepted for publication April 28, 2000.

Address for reprints: James L. Monro, FRCS, Department of Cardiac Surgery, The General Hospital, Tremona Rd, Southampton SO16 6YD, United Kingdom (E-mail: monro1711@aol.com).

J Thorac Cardiovasc Surg 2000;120;820-2

Copyright (C) 2000 by The American Association for Thoracic Surgery

$0022-5223 / 2000 \$ 12.00+0 \quad \mathbf{1 2 / 5 4} / \mathbf{1 0 8 2 8 7}$

doi: $10.1067 / \mathrm{mtc} .2000 .108287$ child at 4 days of age. A diagnosis of tricuspid atresia was made, and she remained well. Cardiac catheterization, performed at 8 months of age, confirmed the diagnosis of tricuspid atresia with a moderate-sized RV and limiting ventricular septal defect. There was a left-to-right shunt of 2:1.

She remained well but became cyanotic and short of breath on exertion at the age of 4 years. A Fontan procedure was then performed (on July 9, 1980), and the RA was connected to the $\mathrm{RV}$ with a size $19 \mathrm{~mm}$ antibiotic-sterilized homograft. At the same time, the atrial and ventricular septal defects were closed.

She made good progress attending a normal school and undertaking sporting activities, but 7 years later, her physical status deteriorated, and further echocardiography and angiography demonstrated moderate homograft regurgitation and stenosis with a gradient of $7 \mathrm{~mm} \mathrm{Hg}$. The RV had grown and was producing satisfactory flow. She had a reoperation, at which the RA-RV conduit was replaced with an 18-mm antibiotic-sterilized homograft.

She initially did well, but 9 years later, she had reduced exercise tolerance and palpitations. Hemodynamic investigations on this occasion showed a high-velocity diastolic flow through the homograft, an RA "a" wave of $16 \mathrm{~mm}$, and an "a" wave gradient of $10 \mathrm{~mm} \mathrm{Hg}$.

At the time of the second reoperation, 16 years after her original modified Fontan procedure, the calcified aortic antibiotic-sterilized homograft was removed. The RA and $\mathrm{RV}$ orifices were widened, and the resulting defects were closed with two valved conduits. The upper one was a 
Shelheigh prepared porcine $23-\mathrm{mm}$ valve mounted on a stent in a tube of pericardium encircled by plastic rings (Shelheigh, Inc, Millburn, NJ). For better hemodynamics, an additional conduit, a $23-\mathrm{mm}$ cryopreserved aortic homograft valve, was placed just below it and sutured to the same atriotomy and ventriculotomy and to the previous heterograft in a double-barreled fashion. The immediate hemodynamic result was satisfactory, with the central venous pressure being $7 \mathrm{~mm} \mathrm{Hg}$ and the arterial systemic pressure being $120 \mathrm{~mm} \mathrm{Hg}$.

Currently, 11 months after the last procedure, she is generally doing well. She does have some palpitations, but a continuous 72-hour electrocardiogram record showed only benign atrial and ventricular ectopic beats. Recent cine-magnetic resonance imaging and echocardiography demonstrated good RV and left ventricular size and function, pulsatile flow within the pulmonary artery with no pulmonary regurgitation, fully patent heterograft and homograft conduits with laminar flow, and no regurgitation or gradients across them (Fig 1, $A$ and $B$ ).

Discussion. In the original description of the Fontan procedure, ${ }^{1}$ the use of homografts to establish atriopulmonary connection was recommended. Homografts are now not usually used; the only indication for their use is in a patient with tricuspid atresia and a good-sized right ventricle. In this situation the connection of the RA with the RV may allow, as we and others have previously documented, ${ }^{2}$ the rudimentary RV to grow sufficiently to support the circulation.

Although the importance of a biventricular circulation has been questioned, ${ }^{3}$ the bulk of clinical and experimental evidence suggests that an RV-dependent, as opposed to an RAdependent, pulmonary circulation provides clear early and late hemodynamic benefits.

Fontan and associates ${ }^{4}$ found that the use of an RA-RV homograft and the RV have yielded a better postoperative functional status, lower RA pressure, and improved left ventricular ejection fraction. Coles and colleagues ${ }^{5}$ reported a survival advantage in patients having a Fontan operation that makes use of the RV. In their combined clinical and experimental animal studies, Ibawi and coworkers ${ }^{6}$ demonstrated that an RV size greater than $30 \%$ of normal increases stroke volume, decreases systemic venous hypertension, and improves left ventricular function. In agreement with others, we believe that if an RA-RV connection is to be used, then a valve should be included because this has been shown to effectively prevent RV-RA reflux. ${ }^{7}$

Despite these hemodynamic advantages, the use of RA-RV homografts carries some widely known problems. They calcify and narrow, necessitating surgical reinterventions for their removal, replacement, or both, whereas their occult obstruction can be the cause of unexpected death. ${ }^{2}$

Apart from the process of calcification, direct pressure exerted on the homografts by the overlying sternum contributes to their obstruction. ${ }^{2,5}$

The technique described here attempts to address these issues. Placing two conduits side by side in a double-barreled manner doubles the cross-sectional area and improves hemodynamics.

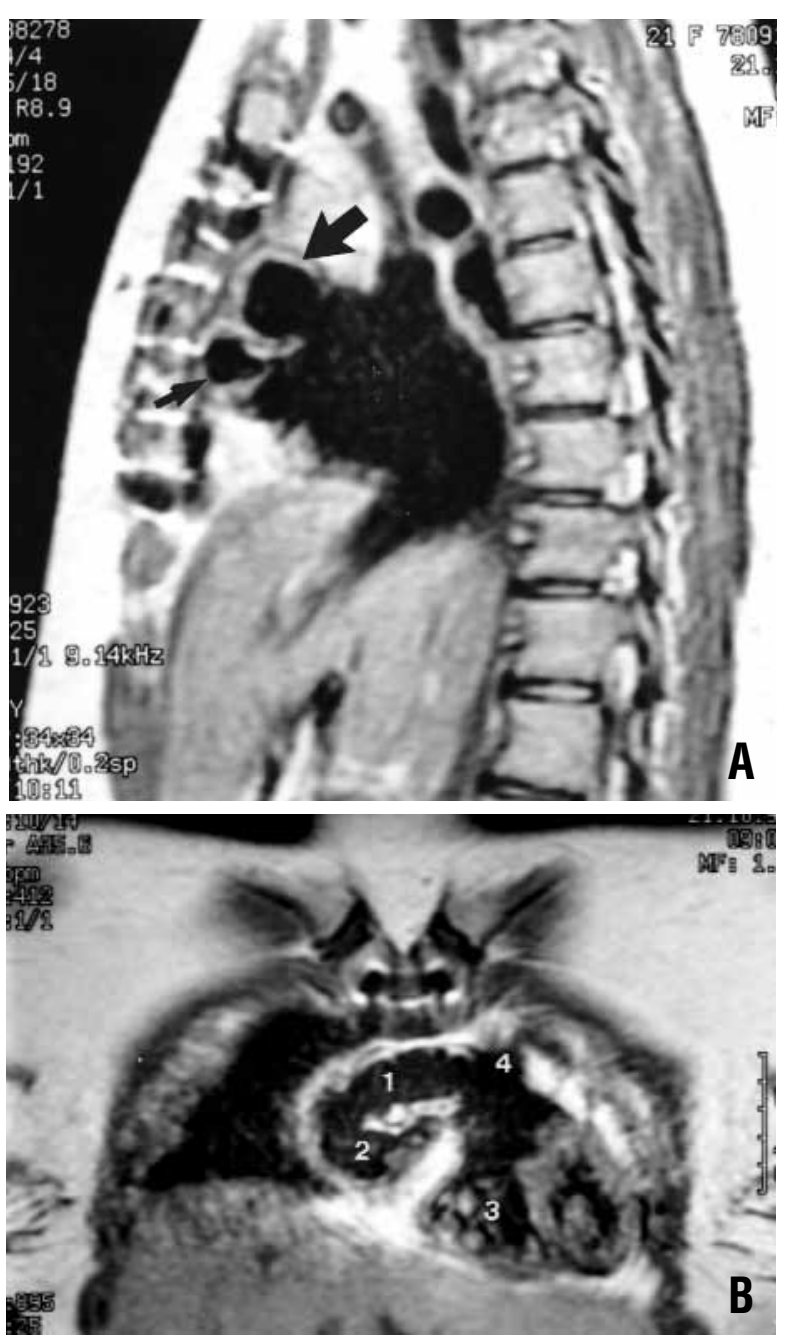

Fig 1. Sagittal (A) and coronal (B) images demonstrate the parallel RA-RV conduits in a retrosternal position. Wide black arrow, Superior (heterograft) conduit; narrow arrow, inferior (homograft) conduit; 1 , superior conduit; 2 , inferior conduit; 3 , right ventricle; 4 , right ventricular outflow tract.

The upper incompressible pig valve prevents compression of the inferior homograft, and ideally, there should be longterm patency. Sternal compression, which has been the cause of homograft narrowing previously, ${ }^{2,5}$ should not affect these valves. The importance of the creation of the largest possible communication in the Fontan circulation, irrespective of the type of connection used, has been well emphasized. ${ }^{8}$

Although longer follow-up to ascertain the merit of this technique is warranted, the results obtained by the recent echocardiographic and cine-magnetic resonance imaging investigations showing good biventricular contractility, pulsatile pulmonary blood flow, no pulmonary regurgitation, and laminar flow with no turbulence, regurgitation, or gradients across the conduits are most encouraging (Fig 1, $A$ and $B$ ). 


\section{REFERENCES}

1. Fontan F, Baudet E. Surgical repair of tricuspid atresia. Thorax 1971;26:240-8.

2. Monro JL, Salmon AP, Keeton BR. The outcome of antibiotic sterilised aortic homografts used in the Fontan procedure. Eur J Cardiothorac Surg 1993;7:360-4.

3. Lee C-N, Schaff HV, Danielson GK, Puga FJ, Driscoll DJ. Comparison of atriopulmonary versus atrioventricular connections for modified Fontan/Kreutzer repair of tricuspid valve atresia. J Thorac Cardiovasc Surg 1986;92:1038-48.

4. Fontan F, Deville C, Quagebeur J, Ottenkamp J, Sourdille N, Choussat A, et al. Repair of tricuspid atresia in 100 patients. J Thorac Cardiovasc Surg 1983;85:647-60.
5. Coles JG, Leung M, Kielmanowicz S, Freedom RM, Benson LN, Rabinovitch M, et al. Repair of tricuspd atresia: utility of right ventricular incorporation. Ann Thorac Surg 1988;45:384-9.

6. Ibawi MN, Idriss FS, DeLeon SY, Kucich VA, Muster AJ, Paul $\mathrm{MH}$, et al. When should the hypoplastic right ventricle be used in a Fontan operation? An experimental and clinical correlation. Ann Thorac Surg 1989;47:533-8.

7. Bull C, de Leval MR, Stark J, Taylor JFN, Macartney FJ. Use of a subpulmonary ventricular chamber in the Fontan circulation. $\mathrm{J}$ Thorac Cardiovasc Surg 1983;85:21-31.

8. Danielson GK. Discussion in: Coles JG, Leung M, Kielmanowicz S, Freedom RM, Benson LN, Rabinovitch M, et al. Repair of tricuspd atresia: utility of right ventricular incorporation. Ann Thorac Surg 1988;45:389. 